\title{
New Achievements in High-Pressure Processing to Preserve Human Milk Bioactivity
}

\author{
Aleksandra Wesolowska ${ }^{1,2 *}$, Elena Sinkiewicz-Darol ${ }^{1,2}$, Olga Barbarska ${ }^{1,3,4}$, Kamila Strom $^{3}$, \\ Malgorzata Rutkowska ${ }^{5}$, Katarzyna Karzel ${ }^{6}$, Elzbieta Rosiak ${ }^{7}$, Gabriela Oledzka $^{3}$, \\ Magdalena Orczyk-Pawiłowicz ${ }^{8}$, Sylwester Rzoska ${ }^{5}$ and \\ Maria Katarzyna Borszewska-Kornacka ${ }^{9}$
}

\begin{abstract}
${ }^{1}$ Laboratory of Human Milk and Lactation Research at Regional Human Milk Bank in Holy Family Hospital, Department of Neonatology, Medical University of Warsaw, Warsaw, Poland, ${ }^{2}$ Human Milk Bank, Ludwik Rydygier' Provincial Polyclinical Hospital in Torun, Torun, Poland, ${ }^{3}$ Department of Medical Biology, Medical University of Warsaw, Warsaw, Poland, ${ }^{4}$ First Department of Obstetrics and Gynecology, Medical University of Warsaw, Warsaw, Poland, ${ }^{5}$ High Pressure Physics, Polish Academy of Science, Warsaw, Poland, ${ }^{6}$ Faculty of Psychology, Warsaw University, Warsaw, Poland, ${ }^{7}$ Department of Food Hygiene and Quality Management, Faculty of Human Nutrition and Consumer Science, Warsaw University of Life Sciences, Warsaw, Poland, ${ }^{8}$ Department of Chemistry and Immunochemistry, Wroclaw Medical University, Wroclaw, Poland, ${ }^{9}$ Neonatal and Intensive Care Department, University Hospital, Medical University of Warsaw, Warsaw, Poland
\end{abstract}

\section{OPEN ACCESS}

Edited by:

Guido Eugenio Moro, Associazione Italiana delle Banche del Latte Umano Donato (AIBLUD), Italy

Reviewed by: María Gormaz,

Agencia Valenciana de Salud, Spain Aakash Pandita,

Sanjay Gandhi Post Graduate Institute of Medical Sciences, India

*Correspondence: Aleksandra Wesolowska aleksandra.wesolowska@wum.edu.p

Specialty section: This article was submitted to Neonatology,

a section of the journal

Frontiers in Pediatrics

Received: 05 August 2018 Accepted: 10 October 2018 Published: 16 November 2018

Citation:

Wesolowska A, Sinkiewicz-Darol E, Barbarska O, Strom K, Rutkowska M, Karzel K, Rosiak E, Oledzka G, Orczyk-Pawiłowicz M, Rzoska S and Borszewska-Kornacka MK (2018) New Achievements in High-Pressure

Processing to Preserve Human Milk Bioactivity. Front. Pediatr. 6:323. doi: 10.3389/fped.2018.00323
High-pressure processing (HPP) is a non-thermal technology that is being increasingly applied in food industries worldwide. It was proposed that this method could be used as an alternative to holder pasteurization ( $\mathrm{HoP} ; 62.5^{\circ} \mathrm{C}, 30 \mathrm{~min}$ ) in milk banks but its impact on the immunologic, enzymatic and hormonal components of human milk has not yet been evaluated in detail. The aim of our study was to compare the effects of HPP in variants: (1) $600 \mathrm{MPa}, 10 \mathrm{~min}$ (2) $100 \mathrm{MPa}, 10 \mathrm{~min}$, interval $10 \mathrm{~min}, 600 \mathrm{MPa}$, 10 min (3) $200 \mathrm{MPa}, 10 \mathrm{~min}$, interval $10 \mathrm{~min}, 400 \mathrm{MPa}, 10 \mathrm{~min}$ (4) $200 \mathrm{MPa}, 10 \mathrm{~min}$, interval $10 \mathrm{~min}, 600 \mathrm{MPa}, 10 \mathrm{~min}$ in temperature range $19-21^{\circ} \mathrm{C}$ and $\mathrm{HoP}$ on the leptin, adiponectin, insulin, hepatocyte growth factor (HGF), lactoferrin and IgG contents in human milk. HoP was done at the Regional Human Milk Bank in Warsaw at the Holy Family Hospital on S90 Eco pasteurizer (Sterifeed, Medicare Colgate Ltd). Apparatus U4000/65 (Unipress Equipment, Poland) was used for pascalization. Milk samples were obtained from women during 2-6 weeks of lactation. Post-treatment culture showed no endogenous bacterial contamination in any tested option. Concentrations of selected components were determined using ELISA tests. The level of all analyzed components were significantly decreased by HoP: leptin $77.86 \%$, adiponectin $32.79 \%$, insulin 32.40\%, HGF 88.72\%, lactoferrin 60.31@.\%, IgG 49.04\%. All HPP variants caused an increase in leptin concentration, respectively (1) $81.79 \%$ (2) $90.01 \%$ (3) 86.12\% (4) 47.96\%. Retention of insulin after HPP was (1) $88.20 \%$ (2) $81.98 \%$ (3) $94.76 \%$ (4) $90.31 \%$ HGF (1) $36.15 \%$ (2) $38.81 \% 97.15 \%$ (3) $97.15 \%$ (4) $43.02 \%$, lactoferrin (1) $55.78 \%$ (2) $57.63 \%$ (3) $78.77 \%$ (4) $64.75 \%$. Moreover, HPP variant as $200+400 \mathrm{MPa}$ preserved lgG (82.24\%) better than HoP and resulted not statistically significant change of adiponectin level (38.55\%) compare to raw milk. Our results showed that HPP leads to preservation of adipokines, growth factor, and lactoferrin, IgG much better or comparable with HoP.

\footnotetext{
Keywords: donor milk, high-pressure processing, milk bank, preterm, adipokines, HGF
} 


\section{INTRODUCTION}

Mother's milk is a natural first choice feed for every newborn, whether born in term or prematurely. Access to human milk is critical especially for very preterm babies for their current health condition and later life prognosis $(1,2)$. In those circumstances, human milk has a not only nutritional function but is a source of non-nutritive bioactive compounds. The presumably, cumulative effects of thousands of substance such as anti-inflammatory agents, immunoglobulins, cytokines, growth factors, oligosaccharides, and bioactive peptides from human milk exist in preventing serious complications of prematurity such as necrotizing enterocolitis (NEC) (3-7). Many of these substances such as hormones and cytokines, even have potential for long -term metabolic programming (8).

Hormones as insulin, leptin, adiponectin have impact on infant growth and body composition. Hepatocyte Growth Factor (HGF) and multifunctional milk protein as lactoferrin act in synergy to support the function of the immature gastrointestinal tract of newborns $(5,9-13)$. Current knowledge about benefit of bioactive factors in breastmilk for infants in early life has results in the increasing number of human milk banks. Therefore, when mother's own milk is unavailable, donor milk is recommended $(2,14)$. Nearly 80 new units located mostly in hospitals specialized in tertiary neonatal centers and NICU were organized in the last decade in European countries alone (15-17). These professional laboratories operate by screening, collecting, processing, and distributing human milk that has been donated by volunteer nursing mothers unrelated to the recipient infant (18). Although human milk banks are well-equipped and organized, the processing of donor milk needs improvements due to the partial loss of its bioactive properties compared with raw milk (19).

Pasteurization used in mostly human milk banks for microbiological purity consists of heating to $62.5^{\circ} \mathrm{C}$ for $30 \mathrm{~min}$ with obvious side effects for many human milk constituents (20). This approach is especially harmful for non-nutritive elements of human milk such as enzymes, hormones, growth factors and cytokines, leading to their diminished presence and activity. Given this side effect of holder pasteurization, new techniques of processing donated human milk are needed to preserve its bioactivity $(19,21)$.

In the present research bioactivity of several components of human milk after standard and innovative high pressure processing were evaluated.

\section{MATERIALS AND METHODS}

\section{Samples Collection}

Milk samples were obtained from 80 donors of the Regional Human Milk Bank in Warsaw at Holy Family Hospital. Donors were given written and verbal instructions on expressing and handling of milk and cleaning of breast pumps. Milk samples were obtained from women (average age was 31 year old) after delivery at term with a surplus of milk during the 2-6 weeks of lactation given informed consent. Samples of $\sim 50 \mathrm{ml}$ of milk were collected at home or in the hospital ward using an electric or manual pump, stored in a refrigerator at temperature $4^{\circ} \mathrm{C}$ and delivered to human milk bank unit within $24 \mathrm{~h}$ while maintaining the refrigeration conditions.

The Bioethics Committee of Warsaw Medical University has accepted the information about conducting this noninterventional study (admission number AKBE/59/15).

\section{Experimental Design and Samples Preparation}

The same volume of milk samples from 2 to 4 donors were pooled to achieve the minimum volume of minimum $125 \mathrm{ml}$ necessary for the study. Each batch was divided into aliquots and exposed to 4 variants of High Pressure Processing (HPP): (1) $600 \mathrm{MPa}$, (2) $200+400 \mathrm{MPa}$, (3) $100+600 \mathrm{MPa}$, (4) $200+600 \mathrm{MPa}$ and holder pasteurization (HoP). The control sample was raw, untreated human milk (Figure 1). The experiments were made three times on independent milk batch.

Following the HPP and HoP treatment all samples as well as raw untreated milk were centrifuged at 4,400 rpm for $15 \mathrm{~min}$ at $4^{\circ} \mathrm{C}$ (Centrifuge 5702R, Eppendorf) after which the fat layer and cells were removed and supernatants were aliquoted into Eppendorf tubes prior to freezing at $-21^{\circ} \mathrm{C}$. Human milk samples were frozen within $48 \mathrm{~h}$ of collection.

Microbiological analysis were performed to verify microbiological purity in the case of selected raw and treated milk samples. The analysis were carried out in three replications to the total number of mesophilic aerobic microorganisms (PN-EN ISO 7218: 2008 / A1: 2013, PN-EN ISO 6887-5: 2010) and the number and Staphylococcus aureus (PN-EN ISO 6888-1: 2001 / A1: 2004).

\section{Treatment}

\section{High Pressure Processing}

Human milk samples were exposed to high pressure treatment at the Institute of High Pressure Physics, Polish Academy of Sciences, using $U$ 4000/65 apparatus (designed and produced by Unipress Equipment). The maximum pressure available in the apparatus was $600 \mathrm{MPa}$, the treatment chamber had a volume of $0.95 \mathrm{~L}$. The pressure-transmitting fluid used was distilled water and polypropylene glycol (1:1). Manufactory designed working temperature of the apparatus ranges from $-10^{\circ} \mathrm{C}$ to $+80^{\circ} \mathrm{C}$. In our experiments, the temperature of the tested condition was between 19 and $21^{\circ} \mathrm{C}$. A pressure of up to $600 \mathrm{MPa}$ was generated in $15-25 \mathrm{~s}$; the release time was $1-4 \mathrm{~s} .19$ and $21^{\circ} \mathrm{C}$. Samples were prepared in 4 variants: (1) $600 \mathrm{MPa}$ (2) $200 \mathrm{MPa}, 10 \mathrm{~min}$; interval $10 \mathrm{~min}$; $400 \mathrm{MPa}, 10 \mathrm{~min}$ (3) $100 \mathrm{MPa}, 10 \mathrm{~min}$; interval $10 \mathrm{~min}$; $600 \mathrm{MPa}, 10 \mathrm{~min}$ (4) $200 \mathrm{MPa}, 10 \mathrm{~min}$; interval, $10 \mathrm{~min} ; 600 \mathrm{MPa}$, $10 \mathrm{~min}$.

\section{Holder Pasteurization}

Holder Pasteurization (HoP) of human milk samples was done at the Regional Human Milk Bank in Warsaw at the Holy Family Hospital on automatic Human Milk Pasteuriser S90 Eco (Sterifeed, Medicare Colgate Ltd). Samples of $50 \mathrm{ml}$ were treated according to Regional Human Milk Bank standard pasteurization protocol at $62.5^{\circ} \mathrm{C}$ for $30 \mathrm{~min}$. The correctness of the process 


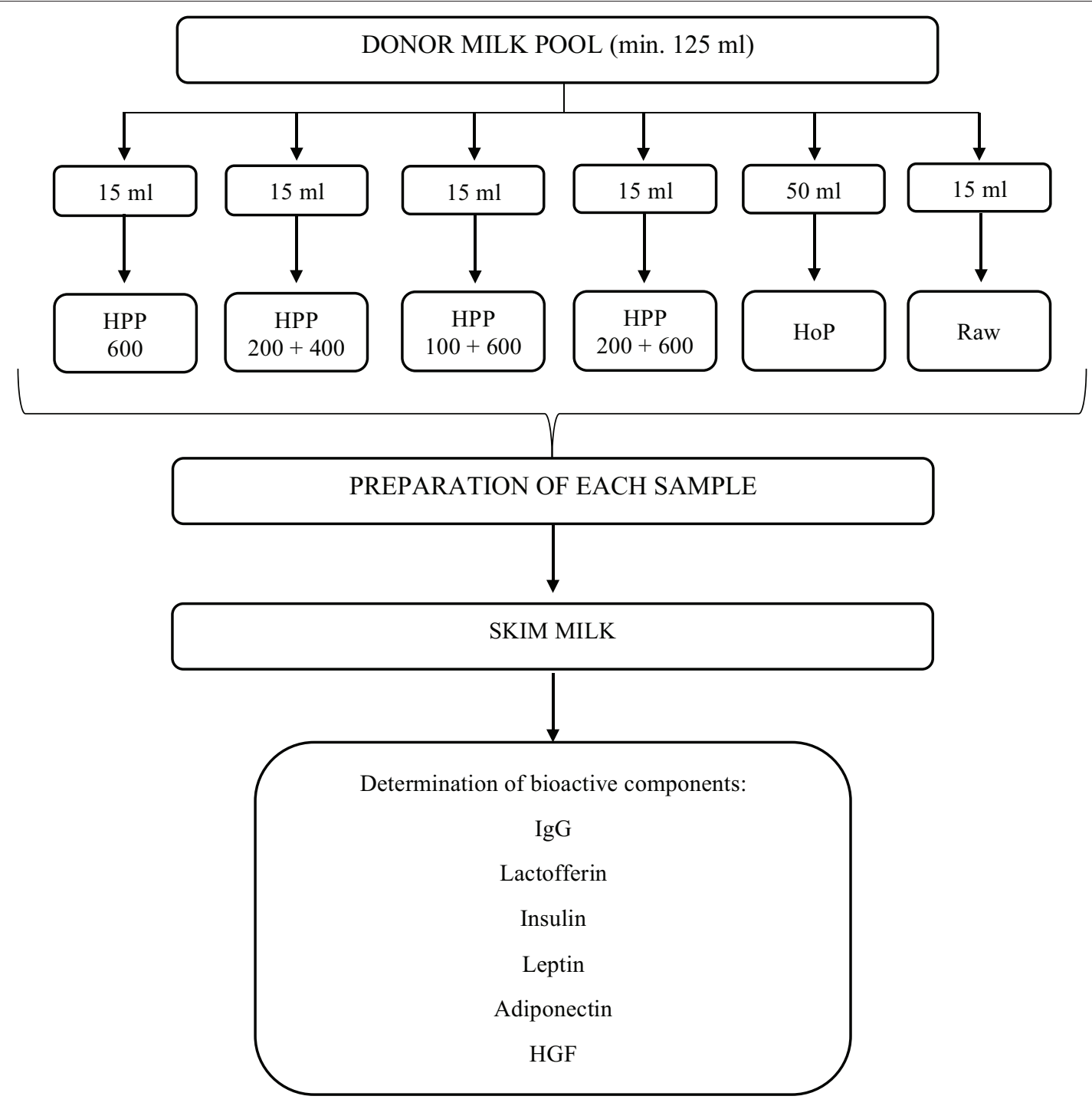

FIGURE 1 | Experimental design of the study.

was confirmed with the data logging system, by recording temperature of the bottle probe every minute.

\section{Determination of Bioactive Components}

All of the bioactive components were determined by the ELISA method. The assay detecting particular components in the milk was done at least in three times using milk samples proccesing in independent experiments. The concentration of $\operatorname{IgG}$ was determined according to a procedure described earlier (22). Briefly: the $\mathrm{F}\left(\mathrm{ab}^{\prime}\right)_{2}$ fragment of goat anti-human IgG (Jackson ImmunoResearch, USA) was used as a coating agent of the wells of a microtiter plate (Nalge Nunc International, Naperville, IL, USA) to bind IgG from the sample. For testing $100 \mu \mathrm{l}$ of $100 \mu \mathrm{l}$ of 100-, 250-, 500-, and 1,000-fold diluted milk and IgG standard preparation from 0.2 to $12.5 \mathrm{ng} / 100 \mu \mathrm{l}$ (Jackson ImmunoResearch, USA) were taken. The amount of IgG bound was quantified by phosphatase-labeled rabbit anti-human IgG
Fc $\gamma$ fragment specific antibodies (Jackson ImmunoResearch, USA).

For lactoferrin determination monoclonal anti-human lactoferrin antibody (ABCAM, Cambridge, UK) was used as a coating agent of the wells of a microtiter plate (Nalge Nunc International, Naperville, IL, USA) to bind lactoferrin from the sample. For testing $100 \mu \mathrm{l}$ of $5000-, 10000-, 25000-$ and 50 000- fold diluted milk and lactoferrin standard preparation from 0.8 to $25 \mathrm{ng} / 100 \mu \mathrm{l}$ (Sigma, St. Louis, MO, USA) were taken. The amount of lactoferrin bound was quantified by phosphatase-labeled rabbit anti-human lactoferrin antibodies (Jackson ImmunoResearch, USA).

The IgG and lactoferrin tests were assayed with 4-nitrophenyl phosphate (SERVA, Heidelberg, Germany) as the enzyme substrate and absorbance was measured in a Stat Fax 2100 Microplate Reader (Awareness Technology Inc., Palm City, FL, USA) at $405 \mathrm{~nm}$ with $630 \mathrm{~nm}$ as the reference filter. All ELISA 
immunobinding and washing steps were carried out in a TRISbuffered saline (TBS, pH 7.5) containing 0.2\% Tween 20. All samples were analyzed at four different sample dilutions, each in duplicate.

The concentrations of leptin, adiponectin, HGF, and insulin were analyzed with commercial ELISA kits using microplates pre-coated with a monoclonal antibody specifically for test substances. The following tests were used: Human Leptin (R\&D Systems, Inc); Human HMW Adiponectin/Acrp30 (R\&D Systems, Inc); Human HGF (R\&D Systems, Inc); Insulin ELISA (DRG Instruments $\mathrm{GmbH}$, Germany). For the study, the option for serum/plasma was chosen as the most adequate for human milk. The method was pre-tested on various samples dilutions as proposed in the protocol. As a result of this validation, the final analyses were performed on undiluted milk. Each sample in ELISA assay was measured in duplicate.

The detections of adiponectin, HGF and leptin, insulin were done by microtiter reader (Synergy HTX multimode reader, Biotek $^{\circledR}$ ) set to $450 \mathrm{~nm}$ with $570 \mathrm{~nm}$ as the reference filter. For data analysis Gen5 Data Analysis Software was used.

\section{Statistics}

Statistical analysis concerns results obtained for six conditions: raw milk, pasteurized milk (HoP), and milk exposed to four variants of high pressure processing (HPP): $600 \mathrm{MPa}, 200 \mathrm{MPa}$ +400 MPa, $100 \mathrm{MPa}+600 \mathrm{MPa}, 200 \mathrm{MPa}+600 \mathrm{MPa}$. As a calculation tool MS Excel was used. The results of determined parameters for each sample are showed as a percentage of the initial value observed for raw milk as $100 \%$. Next, means, SD and $95 \%$ coefficient intervals ( $95 \% \mathrm{CI}$, which refers to $p \leq 0.05$ ) were computed. The actual analysis was based on the overview of overlapping of obtained intervals.

\section{RESULTS}

The average value of the total viable number of microorganisms in raw milk was determined on the level $3.3 \pm 0.90 \log \mathrm{cfu} /$ $\mathrm{ml}$. The number of $S$. aureus was determined at $1.57 \pm 0.65 \mathrm{log}$ $\mathrm{cfu} / \mathrm{ml}$.

Microbiological analyses carried out in pasteurized and pascalised human milk samples did not show the presence of the selected microorganisms (Supplementary Table 1).

The concentration of bioactive components in raw milk samples are shown in Table $\mathbf{1 .}$

Results of our experiments revealed that $\mathrm{HoP}$ caused a statistically significant reduction (49.04\%) in IgG content. HPP variants $600 \mathrm{MPa}, 100 \mathrm{MPa}+600 \mathrm{MPa}$, and $200 \mathrm{MPa}+600 \mathrm{MPa}$ also decreased statistically significantly the IgG content, 69.68, 69.16 , and $68.46 \%$, respectively. The reduction of IgG in $200 \mathrm{MPa}$ $+400 \mathrm{MPa}(17.76 \%)$ was not statistically significant (Table 2, Figure 2A).

In the case of lactoferrin $\mathrm{HoP}$ caused a statistically significant reduction of this protein $(60.31 \%)$ in the human milk. HPP variants $600 \mathrm{MPa}, 100 \mathrm{MPa}+600 \mathrm{MPa}$, and $200 \mathrm{MPa}+600 \mathrm{MPa}$ also decreased the lactoferrin content statistically significantly, $44.22,42.37$, and $35.25 \%$, respectively. The reduction of lactoferrin in $200 \mathrm{MPa}+400 \mathrm{MPa}(21.23 \%)$ was not statistically significant (Table 2, Figure 2B).

Leptin level was significantly reduced by HoP (77.86\%) in comparison to the raw milk. In the matter of high-pressure, all HPP variants caused an increase in leptin concentration, (1) 600 $\mathrm{MPa}$; 81.71\%, (2) $200 \mathrm{MPa}+400 \mathrm{MPa} ; 86.12 \%$, (3) $100 \mathrm{MPa}+$ $600 \mathrm{MPa} ; 90.01 \%$, (4) $200 \mathrm{MPa}+600 \mathrm{MPa}$; 47.96\%, respectively. Indeed, none of the high pressure variants were significantly different from raw milk (Figure 2C).

HoP caused a statistically significant decrease in adiponectin content $(31.19 \%)$ but not so serious as HPP variants $600 \mathrm{MPa}$, $100 \mathrm{MPa}+600 \mathrm{MPa}$, and $200 \mathrm{MPa}+600 \mathrm{MPa}$ which reduced the level of protein almost totally: respectively as 97.99, 89.27, and 95.91\%. The reduction of adiponectin at $200 \mathrm{MPa}+400 \mathrm{MPa}$ was slighter (61.45\%), but also statistically significant (Figure 2D).

Results obtained for HGF were very similar to adiponectin. HoP caused a statistically significant reduction level of HGF detected in human milk (88.72\%). Although the level after HPP treatment by $600 \mathrm{MPa}, 100 \mathrm{MPa}+600 \mathrm{MPa}$, and $200 \mathrm{MPa}+$ $600 \mathrm{MPa}$ was decreased not more than $63.85,61.19$, and $56.98 \%$, respectively, it was still significant. Only when it comes to HPP variant $200 \mathrm{MPa}+400 \mathrm{MPa}$ was the change in HGF level was almost imperceptible and not statistically significant (2.85\%) (Figure 2E).

The level of insulin was diminished under the influence of HoP by $32.40 \%$ in comparison to raw milk. Among of HPP variants only the treatment of human milk by high pressure as $600 \mathrm{MPa}$ caused statistically significant destruction of protein (11.80\%). The reduction in insulin content in human milk after others HPP variants was as following: $200 \mathrm{MPa}+400 \mathrm{MPa}-$ $-5.24 \%, 100 \mathrm{MPa}+600 \mathrm{MPa}-18.02 \%, 200 \mathrm{MPa}+600 \mathrm{Mpa}-$ $-9.69 \%$ but it was not statistically significant (Figure $2 \mathrm{~F}$ ).

The content of selected bioactive compounds in raw milk was assumed as $100 \%$, additionally the range of obtained results (minimum-maximum) was presented as an error bar. The asterisks indicate a pair of results that differ statistically significantly with $p \leq 0.05$.

\section{DISCUSSION}

The human milk donated for human milk banks needs to be of very high quality concerning microbiological safety, nutritional value, and last but not least, bioactivity. For this reason, an operational procedure has been implemented to monitor the whole process of human milk bank activity. National guidelines have been developed in many countries to improve the standards for recruitment, screen the donors and handle and distribute the collected milk (23-25). There are, many minor differences in operational procedure among milk banks in Europe but the pasteurization stage has a common core process. Holder pasteurization has been a "gold standard" in milk banks worldwide for many years. This process involves heating the milk to $62.5^{\circ} \mathrm{C}$ within $30 \mathrm{~min}$. The relatively low temperature and long time parameters (for this reason called also Low Temperature Long Time pasteurization, LTLT) was combined to assure microbiological safety and nutritional value 
TABLE 1 | Concentration of bioactive components in raw milk.

\begin{tabular}{|c|c|c|c|c|c|c|}
\hline & $\begin{array}{c}\lg G \\
(\mu \mathrm{g} / \mathrm{ml})\end{array}$ & $\begin{array}{l}\text { Lactoferrin } \\
(\mathrm{mg} / \mathrm{ml})\end{array}$ & $\begin{array}{l}\text { Leptin } \\
\text { (pg/ml) }\end{array}$ & $\begin{array}{l}\text { Adiponectin } \\
\text { (ng/ml) }\end{array}$ & $\begin{array}{c}\text { HGF } \\
(\mathrm{mlU} / \mathrm{ml})\end{array}$ & $\begin{array}{l}\text { Insulin } \\
\text { (pg/ml) }\end{array}$ \\
\hline Mean $\pm \mathrm{SD}$ & $11.22 \pm 8.83$ & $1.63 \pm 0.47$ & $269.97 \pm 56.53$ & $5.30 \pm 2.05$ & $1306.15 \pm 956.99$ & $10.24 \pm 4.02$ \\
\hline Min. & 5.74 & 1.17 & 226.16 & 2.94 & 413.20 & 6.10 \\
\hline Max. & 21.40 & 2.11 & 333.78 & 3.68 & 2261.00 & 14.67 \\
\hline
\end{tabular}

The results are presented as mean \pm standard deviation with indication on minimum and maximum.

TABLE 2 | Changes in the content of IgG, lactoferrin leptin, adiponectin, HGF, and insulin in human milk after preserving with different methods.

\begin{tabular}{|c|c|c|c|c|c|c|}
\hline \multirow[t]{2}{*}{ Bioactive components } & \multirow[t]{2}{*}{ Raw milk (\%) } & \multirow[t]{2}{*}{ Holder (\%) } & \multicolumn{4}{|c|}{ High-Pressure Processing } \\
\hline & & & $600 \mathrm{MPa}(\%)$ & 100MPa +600 MPa (\%) & $200 \mathrm{MPa}+400 \mathrm{MPa}(\%)$ & $200 \mathrm{MPa}+600 \mathrm{MPa}(\%)$ \\
\hline $\lg G$ & 100 & 50.96 & 30.32 & 30.84 & 82.24 & 31.54 \\
\hline Lactoferrin & 100 & 39.69 & 55.78 & 57.63 & 78.77 & 64.75 \\
\hline Leptin & 100 & 22.14 & 181.71 & 190.01 & 186.12 & 147.96 \\
\hline Adiponectin & 100 & 67.21 & 2.01 & 10.73 & 38.55 & 4.09 \\
\hline HGF & 100 & 11.28 & 36.15 & 38.81 & 97.15 & 43.02 \\
\hline Insulin & 100 & 67.6 & 88.20 & 81.98 & 94.76 & 90.31 \\
\hline
\end{tabular}

The results are presented as a retention percentage compare to the content in raw milk (mean values).

(26). Ever since this technique was incorporated into the milk bank system, it has been known to be damaging for many bioactive milk components, such as vitamins: C, folacin, and B6, poly-unsaturated fatty acids and free fatty acid composition (27-30).

The current knowledge of this topic is summarized in a systematic review by Peila et al. (20). The authors distinguished three groups of human milk components according to the influence from holder pasteurization: those significantly affected such as: enzymes, some cytokines, growth factors: IGF, EPO, HGF, GM-GSF, hormones: insulin, adiponectin, vitamins: B6, ascorbic acid, antioxidant capacity, content of nucleotide monophosphate, free amino acid; Those affected but with contradictory results: immunoglobulins S-IgA, IgM, IgG, lactofferin, lysozyme, some cytokines, some vitamins, total fat content including, saturated fatty acid, - mono and polyunsaturated fatty acid. Fortunately there are some thermal resistance components found in human milk such as some cytokines and growth factors, amino acid, some vitamins: D, E, B2, B5, biotin, B3, B12, antioxidant capacity, lipids, total nitrogen content, human milk oligosaccharides. The great heterogeneity in the available data is partially due to a lack of standardized study protocols in this fields. However, the reduced value of pasteurization is great enough to take immediate steps in searching for a technical solution for milk banks.

HPP is one of the most promising alternatives for thermal treatment, but this sophisticated technique has not yet been validated for human milk. For our study we have chosen those components of human milk that were known to be affected by holder pasteurization but hadn't been evaluated in concern on HPP. We focused on biologically active peptides represented by adiponectin, insulin, leptin and HGF because of its impact on metabolism regulation in newborn. In fact the available data concerning preservation of those human milk components are sparing in details. We could only find one study showing the destruction of insulin and adiponectin under the influence of a standard holder treatment (31). However in case of leptin the work has been done on fast-and slow-heat pasteurization $100^{\circ} \mathrm{C}$ in $5 \mathrm{~min}$ and $57^{\circ} \mathrm{C}$ in $30 \mathrm{~min}$, respectively (32). In all these cases, it was observed that the active peptin level was diminished in the range of 30-40\% compared to unpasteurized milk.

Moreover, we included in our research two immunologically important proteins from human milk such as immunoglobulin G (IgG) and lactoferrin. Preservation on immunocomponents in donor milk, are well documented in spite of contradictory results (33-38). Nevertheless, we used those two components as an indicator to compare with trends observed for biologically active peptides of non-nutrition value after thermal and high pressure treated milk.

In our study the mean IgG concentration in untreated milk samples was $11.22 \pm 8.83 \mu \mathrm{g} / \mathrm{ml}$ (range $5.74-21.40 \mu \mathrm{g} / \mathrm{ml}$ ) Table 1. IgG is reported as a very sensitive immunoglobulin with IG4 subclass which was thermal resistance. The loss in the case of holder pasteurization is about $50 \%$ relative to untreated milk. Our results are consistent with others, reported by Sousa et al. (38). Only one of the HPP variants $(200 \mathrm{MPa}+400 \mathrm{MPa})$ did not statistically significantly decrease the IgG content in milk samples (reduction 17.76\%) and gave results better than holder pasteurization (Figure 2A).

In the case of lactoferrin the mean concentration detected in raw milk samples was $1.63 \pm 0.47 \mathrm{mg} / \mathrm{ml}$ (range 1.17-2.11 $\mathrm{mg} / \mathrm{ml}$ ) which is similar to those reported in the literature (39) (Table 1) The reduction of lactoferrin level by HoP in current experiments is $60 \%$ of the level detected in raw milk samples. The 


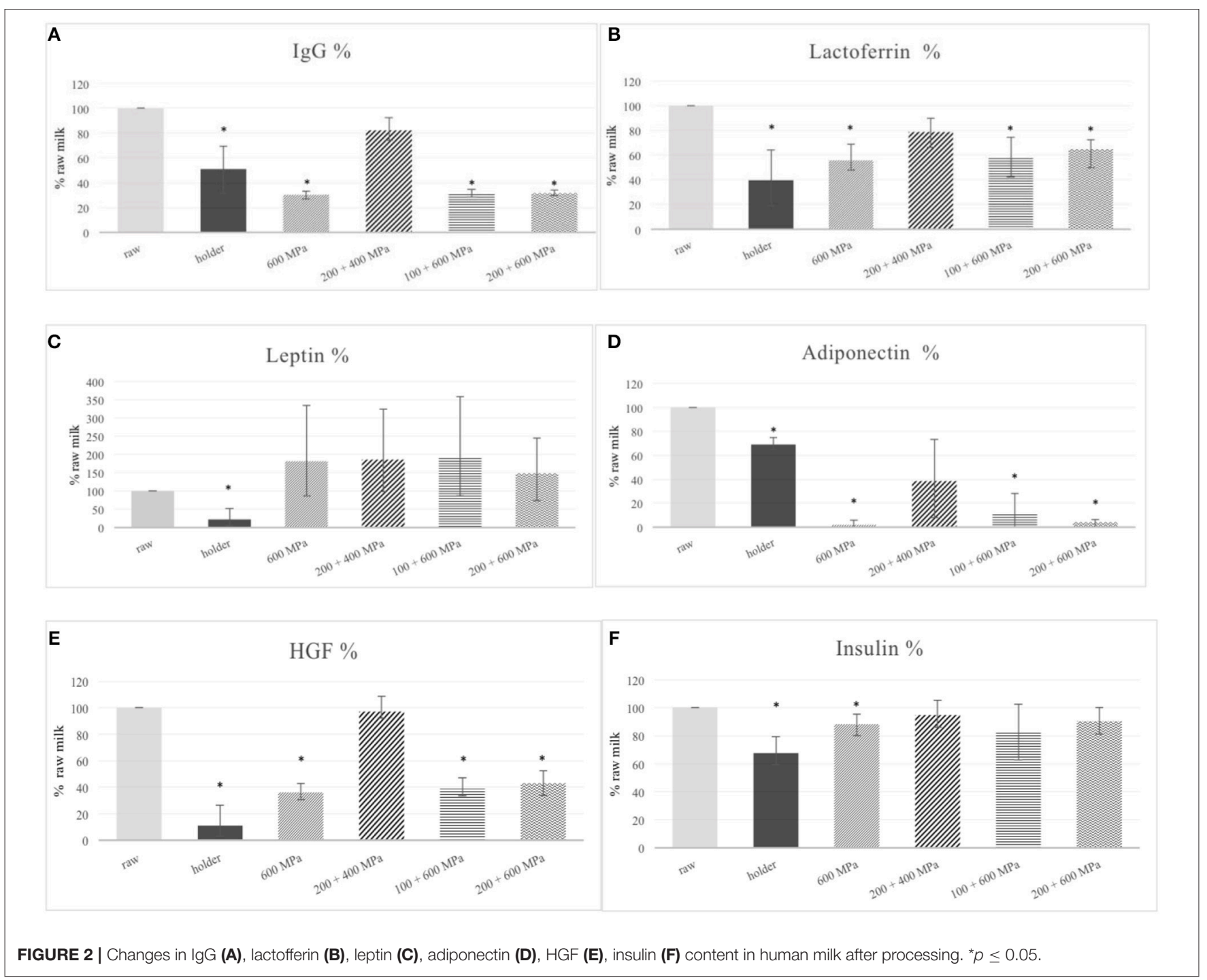

difference was statistically significant. It is in the range from 35 to $90 \%$ losses observed by others researches. Still it is twice more preserve than was reported by Christen et al. as a $20 \%$ retention after HoP (36). All HPP variants used in this study better preserved lactoferrin in human milk than holder pasteurization. Because of the great variance of data the difference was not statistically significant. However, we could see that the best option of HPP is $200 \mathrm{MPa}+400 \mathrm{MPa}$ variant, which resulted only $21.23 \%$ diminished of lactoferrin level which was not statistically significant comparing to raw milk (Figure 2B).

Taking into account the importance of short and long lasting outcome of donor milk nutritional therapy, we decided to extend the research in to evaluate the possibility to preserve the biologically active peptides found in human milk as key metabolism regulation components.

We suspected that HPP variant $200 \mathrm{MPa}+400 \mathrm{MPa}$ already tested with success for immunocomponents preservation, will be preferable in comparison to thermal treatment, for hormones such as leptin, adiponectin, insulin, and HGF as well.
As was revealed before, HPP was even most effective as holder pasteurization in the elimination of inoculated microbiological flora of human milk (40). In our current study HPP was able to eliminate commensal bacteria of donors milk successfully (Supplementary Data).

The most recent update of Cochrane metaanalysis which evaluated growth and development of preterm born infants fed with formula comparing with donor milk has proven that supplementing mother's milk with pasteurized human milk results in lower rates of weight gain, linear growth and head growth (41). Although it is more important that diet based on solely human milk reduces the NEC risk, hesitation about the consequence of long term under nutrition remains. In this context it seems to be most important to preservation donor milk components with regulation metabolism properties.

Among adipokines derived from human milk, leptin, and adiponectin, have great impacts on the neonatal growth and development. Leptin is a key factor in the regulation of energy 
balance and appetite $(42,43)$. Blood leptin concentration in Small for-Gestational Age (ang. SGA) neonates has been observed to be inversely related to rates of intrauterine growth, suggesting a possible role of leptin in promoting fetus growth (44). Leptin in human milk appears from mammary epithelial cells in milk fat globules as well as being transferred from material blood $(45,46)$. Leptin receptors have been identified in the human small intestine, which suggests that breast milk leptin could play a role in the short-term control of food intake in neonates (47).

In our experiments, leptin hormone was detected in all analyzed milk samples before and after processing. The mean concentration of leptin in raw milk samples was $269.97 \pm$ $56.53 \mathrm{pg} / \mathrm{ml}$ (range $226.16-333.78 \mathrm{pg} / \mathrm{ml}$ ) which is similar to those reported in the literature (48) (Table 1). Leptin seems to be a thermolabile protein, therefore it is not uncommon that treatment in $62.5^{\circ} \mathrm{C}$ by $30 \mathrm{~min}$ decreases the detectable level more than $70 \%$, more slightly sterilization condition as $57^{\circ} \mathrm{C}$ caused comparable results, as was shown earlier. Surprisingly, after high pressure processing we even detected an increase relative to untreated milk (Figure $2 \mathrm{C}$, Table 2). This phenomena could be explained by the influence of hydrostatic pressure on the physicochemical property of human milk. Human milk is a very complex biological fluid that could be characterized simply as an emulsion of fat globules in an aqueous liquid with cells components. As was shown leptin is located predominantly in emulsion phase of human milk, which consists of the milk fat droplet or fat-associated proteins. Some portion of human milk leptin is locally synthesized in mammary epithelium cells. In fact documented effects of high pressure on milk lipids have been scarce. However, milk fat globules appear to remain intact under pressure, some alternation in globule size being observed (49). It is not ruled out that pascalization of human milk causes the release of leptin incorporated in milk fat globule or in cellular component of human milk. Indeed, because of high variance, the results after HPP treatment were not statistically significantly different from raw milk.

In the case of adiponectin, the mean concentration detected in raw milk samples was $5.30 \pm 2.05 \mathrm{ng} / \mathrm{ml}$ (range $2.94-3.68 \mathrm{ng} / \mathrm{ml}$ ) which was comparable to others findings (Table 1 ). The average quantity of adiponectin in human milk detected by Martin LJ and coworkers was $\sim 19 \mathrm{ng} / \mathrm{ml}$ (range $4-88 \mathrm{ng} / \mathrm{ml}$ ) (50). In another study median adiponectin concentration in human milk was $9.99 \mathrm{ng} / \mathrm{ml}$ (range $3.59-20.52 \mathrm{ng} / \mathrm{ml}$ ). Adiponectin levels remain well detectable throughout the time of breastfeeding with a high level at the beginning of the course of lactation and with a decrease at the time of the introduction of complementary feeding (51). Adiponectin, synthesized by adipocytes, exists in plasma as a several different oligomeric proteins. Highmolecular-weight (HMW) adiponectin is a large multimer of 12-18 subunits, thought to be the most biologically active form almost entirely existing in human milk (9). Therefore, we evaluated this particular form of protein in the human milk after processing. We have detected HMV adiponectin in all analyzed human milk samples and we could observed that all methods of treatment significantly decreased the content of adiponectin in milk samples compared to raw milk (Figure 2D, Table 2). Fortunately, the reduction of adiponectin in HPP variant 200
$\mathrm{MPa}+400 \mathrm{MPa}$ was not so radical but not very much different from after HoP. As was mentioned earlier, because of the crucial role adiponectin in the regulation of insulin sensitivity in the offspring, reduction of functional hormone in donor milk could be especially problematic for very preterm infants who are at increased risk of insulin resistance and type 2 diabetes later in life (32).

The mean concentration of HGF in raw milk samples was $1306.15 \pm 956.99 \mathrm{mlU} / \mathrm{ml}$ (range 413.20-2261 $\mathrm{mlU} / \mathrm{ml}$ ) (Table 1). In spite of concentrations of HGF in human milk is dependent on many factors including selection of the study group and demographic variables, but the stage of lactation seems to be crucial (52). The HGF level in colostrum is 20-30 higher than in mature milk, which stresses the key role of this growth factor in the development progress of newborns. Moreover, the concentration of HGF in milk from mothers delivered preterm were significantly higher than those from term deliveries. As was speculated earlier, it was finally discovered that trophic action of HGF from human milk occurs by the stimulation of gastrointestinal (GI) epithelial cells $(53,54)$. In this context, the presence of HGF in donor milk could represent a special benefit in prevention of such serious GI track illnesses such as NEC. As was $n$ in Figure 2E the HGF level after treatment by HPP 200 $\mathrm{MPa}+400 \mathrm{MPa}$ did not significantly differ from the level in raw milk but it was significantly higher than the level of HGF in milk subjected to other high pressure variants or HoP.

Insulin has been detected at very high levels in the human colostrum of healthy mothers (114-306 mU/L) after that decreasing by day 5 postpartum to the physiological levels at the fasting state (55). Insulin seems to be actively transported into milk irrespective of the source because exogenous insulin used for treatment of type 1 diabetes is found in human milk. Surprisingly, that levels of insulin are significantly higher in milk from type 1 diabetic mothers than that of non-diabetic control mothers (56). As has been show earlier, insulin derived from derived insulin could work effectively in newborn exerted hormone dependent effect to glucose homeostasis (57). In addition to the key role of insulin in blood glucose the homeostasis, the properties of dietary hormone in influencing growth and development of the small intestine was postulated (58). Recent studies have shown the link of human milk hormone occurrence, as insulin as well as leptin, with the proper pattern of intestinal microbiome in neonates (59).

In our study the mean insulin concentration in raw milk samples was $10.24 \pm 4.02 \mathrm{pg} / \mathrm{ml}$ (range 6.10-14.67 pg/ml) which is similar to data reported in the literature (60) Table 1. Thermal treatment used in experiments affect significantly the content of insulin in pasteurized human milk compared to raw milk. The pasteurization changes occurred were comparable with the remarkable decreased observed by Ley (32) (Figure 2F). In the case of three out of four HPP variants, including HPP $200 \mathrm{MPa}$ +400 $\mathrm{MPa}$, they gave results significantly better than holder pasteurization.

In conclusion, our experiments showed that the $200+400 \mathrm{MPa}$ variant is the best option of high pressure to preserve several metabolic hormones and immunocomponents of human milk. Our findings with persistent bioactive peptides in pascalized 
human milk is in line with the earliest reports concerning retention of others hormones after HPP with great significance for the infant's health $(21,61,62)$.

We showed, for the first time, preservation of several metabolic hormones in donor milk HPP processing. Growing recent studies in nutritional therapy of preterm's have emphasized the role of our discovery $(63,64)$.

We believed that preservation of important bioactive peptides as hormones and growth factors in human milk is especially important in the context of delivering donor milk for very preterm infants.

\section{LIMITATION OF THE STUDY AND FUTURE DIRECTION}

Lack of protocol for evaluation of new techniques was a severe obstacle to improving the pasteurization stage of donor milk. In the next step we would like to follow current expert's recommendation for validation of new method of human milk processing and fit designed methodology for this, especially in the matter of microbiology.

\section{AUTHOR CONTRIBUTIONS}

AW: main contributions to the conception and design of the work, analysis and interpretation of data for the work, drafting the work. ES-D and OB: acquisition, analysis and interpretation of data for the work, revising it critically for important intellectual content. KS and MR: acquiring the main part of the data used for the work. KK statistical analysis and interpretation

\section{REFERENCES}

1. Boyd CA, Quigley MA, Brocklehurst P. Donor breast milk versus infant formula for preterm infants: systematic review and metaanalysis. Arch Dis Childhood Fetal Neonat Edn. (2007) 92:F169-75. doi: $10.1136 /$ adc. 2005.089490

2. Moro GE, Arslanoglu S, Bertino E, Corvaglia L, Montirosso R, Picaud JC, et al. Human milk in feeding premature infants: consensus statement. J Pediatr Gastroenterol Nutr. (2015) 61:S16-9. doi: 10.1097/01.mpg.0000471460.08792.4d

3. Sisk P, Lovelady C, Dillard R, Gruber K, O'shea T. Early human milk feeding is associated with a lower risk of necrotizing enterocolitis in very low birth weight infants. J Perinatol. (2007) 27:428. doi: 10.1038/sj.jp. 7211758

4. Meinzen-Derr J, Poindexter B, Wrage L, Morrow A, Stoll B, Donovan E. Role of human milk in extremely low birth weight infants' risk of necrotizing enterocolitis or death. J Perinatol. (2009) 29:57. doi: 10.1038/jp.2008.117

5. Savino F, Liguori SA, Lupica MM. Adipokines in breast milk and preterm infants. Early Hum Dev. (2010) 86(Suppl. 1):77-80. doi: 10.1016/j.earlhumdev.2010.01.011

6. Herrmann K, Carroll K. An exclusively human milk diet reduces necrotizing enterocolitis. Breastfeed Med. (2014) 9:184-90. doi: 10.1089/bfm. 2013.0121

7. Kantorowska A, Wei JC, Cohen RS, Lawrence RA, Gould JB., Lee HC. Impact of donor milk availability on breast milk use and necrotizing enterocolitis rates. Pediatrics (2016) 137:e20153123. doi: 10.1542/peds2015-3901

8. Ballard O, Morrow AL. Human milk composition: nutrients and bioactive factors. Pediatr Clin. (2013) 60:49-74. doi: 10.1016/j.pcl.2012.10.002 of data for the work. ER: acquiring part of the data for the work. GO, SR, and MB-K: revising it critically for important intellectual content, providing approval for publication of the content. MO-P: acquiring part of the data for the work, revising it critically for important intellectual content. All authors agree to be accountable for all aspects of the work in ensuring that questions related to the accuracy or integrity of any part of the work are appropriately investigated and resolved.

\section{FUNDING}

This work was funded by the Polish National Centre for Research and Development Social Innovation grant for project Lactotechnology as an answer to special nutritional requirements of preterm infants IS-81/NCBIR/2015. The authors thank the Italian Association of Human Milk Banks (Milan, Italy) for covering the cost of this publication.

\section{ACKNOWLEDGMENTS}

We acknowledge Elzbieta Lodykowska from the Regional Human Milk Bank in Warsaw at Holy Family Hospital for assistance with collecting milk samples and all the mothers who participated the study.

\section{SUPPLEMENTARY MATERIAL}

The Supplementary Material for this article can be found online at: https://www.frontiersin.org/articles/10.3389/fped. 2018.00323/full\#supplementary-material

9. Newburg DS, Woo JG, Morrow AL. Characteristics and potential functions of human milk adiponectin. J Pediatr. (2010) 156:S41-6. doi: 10.1016/j.jpeds.2009.11.020

10. Garcia C, Duan R-D, Brévaut-Malaty V, Gire C, Millet V, Simeoni U, et al. Bioactive compounds in human milk and intestinal health and maturity in preterm newborn: an overview. Cell Mol Biol. (2013) 59:108-31. doi: 10.1170/T952

11. Wada Y, Lönnerdal B. Bioactive peptides derived from human milk proteins-mechanisms of action. J Nutr Biochem. (2014) 25:503-14. doi: 10.1016/j.jnutbio.2013.10.012

12. Brunner S, Schmid D, Zang K, Much D, Knoeferl B, Kratzsch J, et al. Breast milk leptin and adiponectin in relation to infant body composition up to 2 years. Pediatr Obes. (2015) 10:67-73. doi: 10.1111/j.2047-6310.2014.222.x

13. Fields DA, Schneider CR, Pavela G. A narrative review of the associations between six bioactive components in breast milk and infant adiposity. Obesity (2016) 24:1213-21. doi: 10.1002/oby.21519

14. Breastfeeding and the use of human milk. Pediatrics (2012) 129:e827-41. doi: 10.1542/peds.2011-3552

15. Arslanoglu S, Corpeleijn W, Moro G, Braegger C, Campoy C, Colomb $\mathrm{V}$, et al. Donor human milk for preterm infants: current evidence and research directions. J Pediatr Gastroenterol Nutr. (2013) 57:535-42. doi: 10.1097/MPG.0b013e3182a3af0a

16. Haiden N, Ziegler EE. Human milk banking. Ann Nutr Metab. (2016) 69(Suppl. 2):7-15. doi: 10.1159/000452821

17. Moro GE. History of milk banking: from origin to present time. Breastfeed Med. (2018) 13:S-16-17. doi: 10.1089/bfm.2018.29077.gem

18. Picaud J-C, Buffin R. Human milk-treatment and quality of banked human milk. Clin Perinatol. (2017) 44:95-119. doi: 10.1016/j.clp.2016.11.003 
19. Peila C, Emmerik NE, Giribaldi M, Stahl B, Ruitenberg JE, Van Elburg RM, et al. Human milk processing: a systematic review of innovative techniques to ensure the safety and quality of donor milk. J Pediatr Gastroenterol Nutr. (2017) 64:353-61. doi: 10.1097/MPG.0000000000001435

20. Peila C, Moro GE, Bertino E, Cavallarin L, Giribaldi M, Giuliani F, et al. The effect of holder pasteurization on nutrients and biologically-active components in donor human milk: a review. Nutrients (2016) 8:E477. doi: 10.3390/nu8080477

21. Sousa SG, Delgadillo I, Saraiva JA. Human milk composition and preservation: evaluation of high-pressure processing as a nonthermal pasteurization technology. Crit Rev Food Sci Nutr. (2016) 56:1043-60. doi: 10.1080/10408398.2012.753402

22. Lis-Kuberka J, Orczyk-Pawiłowicz M, Królak-Olejnik B, BerghausenMazur M, Baranska K, Katnik-Prastowska I. Lectin-based analysis of human milk immunoglobulin $G$ fucosylated variants in relation to milk maturation and perinatal risk factors. J Appl Biomed. . (2018) 16:232-40. doi: 10.1016/j.jab.2018.02.001

23. Arslanoglu S, Bertino E, Tonetto P, De Nisi G, Ambruzzi AM, Biasini A, et al. Guidelines for the establishment and operation of a donor human milk bank: Italian Association of Human Milk Banks Associazione Italiana Banche del Latte Umano Donato (AIBLUD: https://www.aiblud.com/). J Mater Fetal Neon Med. (2010) 23:1-20. doi: 10.3109/14767058.2010.512414

24. Picaud J-C. VIII. Human milk banks: how to organize the collection of human milk to feed preterm infants. J Pediatr Gastroenterol Nutr. (2015) 61:S10-2. doi: 10.1097/01.mpg.0000471456.78296.a6

25. Calvo J, Lara NRG, Gormaz M, Pena M, Lorenzo MJM, Murillo PO, et al. Recommendations for the creation and operation of maternal milk banks in Spain. An Pediatr. (2018) 89:65.e1-e6. doi: 10.1016/j.anpede.2018. 01.007

26. Wills M, Han V, Harris D, Baum J. Short-time low-temperature pasteurisation of human milk. Early Hum Dev. (1982) 7:71-80. doi: 10.1016/0378-3782(82)90009-3

27. Wardell JM, Hill C, Souza S. Effect of pasteurization and of freezing and thawing human milk on its triglyceride content. Acta Paediatr. (1981) 70:46771. doi: 10.1111/j.1651-2227.1981.tb05724.x

28. Van Zoeren-Grobben D, Schrijver J, Van den Berg H, Berger H. Human milk vitamin content after pasteurisation, storage, or tube feeding. Arch Dis Child. (1987) 62:161-5. doi: 10.1136/adc.62.2.161

29. Lepri L, Del Bubba M, Maggini R, Donzelli GP, Galvan P. Effect of pasteurization and storage on some components of pooled human milk1. J Chromatogr B Biomed Sci Appl. (1997) 704:1-10. doi: 10.1016/S0378-4347(97)00439-8

30. Wight NE. Donor human milk for preterm infants. J Perinatol. (2001) 21:249. doi: 10.1038/sj.jp.7200533

31. Resto M, O'Connor D, Leef K, Funanage V, Spear M, Locke R. Leptin levels in preterm human breast milk and infant formula. Pediatrics (2001) 108:e15. doi: 10.1542/peds.108.1.e15

32. Ley SH, Hanley AJ, Stone D, O'Connor DL. Effects of pasteurization on adiponectin and insulin concentrations in donor human milk. Pediatr Res. (2011) 70:278-81. doi: 10.1203/PDR.0b013e31822 4287a,

33. Goldsmith SJ, Dickson JS, Barnhart HM, Toledo RT, Eiten-Miller RR. IgA, IgG, IgM and lactoferrin contents of human milk during early lactation and the effect of processing and storage. J Food Prot. (1983) 46:4-7. doi: 10.4315/0362-028X-46.1.4

34. Koenig Á, de Albuquerque Diniz EM, Barbosa SF, Vaz FA. Immunologic factors in human milk: the effects of gestational age and pasteurization. J Hum Lact. (2005) 21:439-43. doi: 10.1177/0890334405280652

35. Baro C, Giribaldi M, Arslanoglu S, Giuffrida MG, Dellavalle G, Conti A, et al. Effect of two pasteurization methods on the protein content of human milk. Front Biosci. (2011) 3:818-29. doi: 10.2741/289

36. Christen L, Lai CT, Hartmann B, Hartmann PE, Geddes DT. The effect of UV-C pasteurization on bacteriostatic properties and immunological proteins of donor human milk. PLoS ONE (2013) 8:e78586. doi: 10.1371/journal.pone.0085867

37. Mayayo C, Montserrat M, Ramos S, Martínez-Lorenzo M, Calvo M, Sánchez L, et al. Kinetic parameters for high-pressure-induced denaturation of lactoferrin in human milk. Int Dairy J. (2014) 39:246-52. doi: 10.1016/j.idairyj.2014.07.001

38. Sousa SG, Delgadillo I, Saraiva JA. Effect of thermal pasteurisation and high-pressure processing on immunoglobulin content and lysozyme and lactoperoxidase activity in human colostrum. Food Chem. (2014) 151:79-85. doi: 10.1016/j.foodchem.2013.11.024

39. Villavicencio A, Rueda MS, Turin CG, Ochoa TJ. Factors affecting lactoferrin concentration in human milk: how much do we know? Biochem Cell Biol. (2016) 95:12-21. doi: 10.1139/bcb-2016-0060

40. Windyga B, Rutkowska M, Sokołowska B, Skapska S, Wesołowska A, Wilinska $\mathrm{M}$, et al. Inactivation of Staphylococcus aureus and native microflora in human milk by high pressure processing. High Press Res. (2015) 35:181-8. doi: 10.1080/08957959.2015.1007972

41. Quigley M, Embleton N, McGuire W. Formula versus donor breast milk for feeding preterm or low birth weight infants. Cochr Database Syst Rev. (2018) 6:CD002971. doi: 10.1002/14651858.CD002971.pub4

42. Palou A, Picó C. Leptin intake during lactation prevents obesity and affects food intake and food preferences in later life. Appetite (2009) 52:249-52. doi: 10.1016/j.appet.2008.09.013

43. Langhans W, Geary $\mathrm{N}$, editors. Frontiers in Eating and Weight Regulation. Forum of Nutrition, Vol. 63. Basel: Karger (2010), p. 84-93. doi: 10.1159/000264396

44. Koistinen HA, Koivisto V, Andersson S, Karonen S-L, Kontula K, Oksanen L, et al. Leptin concentration in cord blood correlates with intrauterine growth. J Clin Endocrinol Metab. (1997) 82:3328-30. doi: 10.1210/jc.82.10.3328

45. Casabiell X, Pineiro V, Tome M, Peino R, Dieguez C, Casanueva F. Presence of leptin in colostrum and/or breast milk from lactating mothers: a potential role in the regulation of neonatal food intake. J Clin Endocrinol Metab. (1997) 82:4270-3. doi: 10.1210/jcem.82.12.4590

46. Bonnet M, Delavaud C, Laud K, Gourdou I, Leroux C, Djiane J, et al. Mammary leptin synthesis, milk leptin and their putative physiological roles. Reprod Nutr Dev. (2002) 42:399-413. doi: 10.1051/rnd:2002034

47. Barrenetxe J, Villaro AC, Guembe L, Pascual I, Munoz-Navas M, Barber A, et al. Distribution of the long leptin receptor isoform in brush border, basolateral membrane, and cytoplasm of enterocytes. Gut (2002) 50:797-802. doi: 10.1136/gut.50.6.797

48. Kugananthan S, Lai CT, Gridneva Z, Mark PJ, Geddes DT, Kakulas F. Leptin levels are higher in whole compared to skim human milk, supporting a cellular contribution. Nutrients (2016) 8:E711. doi: 10.3390/nu8110711

49. Huppertz T, Kelly AL, Fox PF. Effects of high pressure on constituents and properties of milk. Int Dairy J. (2002) 12:561-72. doi: 10.1016/S0958-6946(02)00045-6

50. Martin LJ, Woo JG, Geraghty SR, Altaye M, Davidson BS, Banach W, et al. Adiponectin is present in human milk and is associated with maternal factors. Am J Clin Nutr. (2006) 83:1106-11. doi: 10.1093/ajen/83.5.1106

51. Bronsky J, Mitrova K, Karpisek M, Mazoch J, Durilova M, Fisarkova B, et al. Adiponectin, AFABP, and leptin in human breast milk during 12 months of lactation. J Pediatr Gastroenterol Nutr. (2011) 52:474-7. doi: 10.1097/MPG.0b013e3182062fcc

52. Munblit D, Treneva M, Peroni DG, Colicino S, Chow L, Dissanayeke S, et al. Colostrum and mature human milk of women from London, Moscow, and Verona: determinants of immune composition. Nutrients (2016) 8:695. doi: 10.3390/nu8110695

53. Yamada Y, Saito S, Morikawa H. Hepatocyte growth factor in human breast milk. Am J Reprod Immunol. (1998) 40:112-20. doi: 10.1111/j.1600-0897.1998.tb00399.x

54. Itoh H, Itakura A, Kurauchi O, Okamura M, Nakamura H, Mizutani S Hepatocyte growth factor in human breast milk acts as a trophic factor. Hormone Metab Res. (2002) 34:16-20. doi: 10.1055/s-2002-19961

55. Kulski J, Hartmann P. Milk insulin, GH and TSH: relationship to changes in milk lactose, glucose and protein during lactogenesis in women. Endocrinol Exp. (1983) 17:317-26.

56. Whitmore T, Trengove N, Graham D, Hartmann P. Analysis of insulin in human breast milk in mothers with type 1 and type 2 diabetes mellitus. Int I Endocrinol. (2012) 2012:296368. doi: 10.1155/2012/296368

57. Koldovsky O. Hormones in milk. In: Litwack G, editor. Vitamins and Hormones, Vol. 50. 1st ed. (1995). p. 77-149. 
58. Shehadeh N, Sukhotnik I, Shamir R. Gastrointestinal tract as a target organ for orally administered insulin. J Pediatr Gastroenterol Nutr. (2006) 43:276-81. doi: 10.1097/01.mpg.0000226377.03247.fb

59. Gotteland M, Magne F. Alterations in human milk leptin and insulin are associated with early changes in the infant intestinal microbiome. Am J Clin Nutr. (2017) 105:234-234. doi: 10.3945/ajcn.116.140129

60. Shehadeh N, Khaesh-Goldberg E, Shamir R, Perlman R, Sujov P, Tamir A, et al. Insulin in human milk: postpartum changes and effect of gestational age. Arch Dis Child Fetal Neonat Edn. (2003) 88:F214-6. doi: 10.1136/fn.88. 3.F214

61. Viazis S, Farkas BE, Allen JC. Effects of high-pressure processing on immunoglobulin A and lysozyme activity in human milk. J Hum Lact. (2007) 23:253-61. doi: 10.1177/0890334407303945

62. Permanyer M, Castellote C, Ramirez-Santana C, Audi C, Perez-Cano FJ, Castell $\mathrm{M}$, et al. Maintenance of breast milk Immunoglobulin A after high-pressure processing. J Dairy Sci. (2010) 93:877-83. doi: 10.3168/jds. 2009-2643

63. Hair AB, Peluso AM, Hawthorne KM, Perez J, Smith DP, Khan JY, et al. Beyond necrotizing enterocolitis prevention: improving outcomes with an exclusive human milk-based diet. Breastfeed Med. (2016) 11:70-4. doi: $10.1089 /$ bfm.2015.0134

64. Miller J, Tonkin E, Damarell RA, McPhee AJ, Suganuma M, Suganuma $\mathrm{H}$, et al. A systematic review and meta-analysis of human milk feeding and morbidity in very low birth weight infants. Nutrients (2018) 10:E707. doi: $10.3390 /$ nu10060707

Conflict of Interest Statement: The authors declare that the research was conducted in the absence of any commercial or financial relationships that could be construed as a potential conflict of interest.

Copyright (c) 2018 Wesolowska, Sinkiewicz-Darol, Barbarska, Strom, Rutkowska, Karzel, Rosiak, Oledzka, Orczyk-Pawiłowicz, Rzoska and Borszewska-Kornacka. This is an open-access article distributed under the terms of the Creative Commons Attribution License (CC BY). The use, distribution or reproduction in other forums is permitted, provided the original author(s) and the copyright owner(s) are credited and that the original publication in this journal is cited, in accordance with accepted academic practice. No use, distribution or reproduction is permitted which does not comply with these terms. 